\title{
Joaquim de Carvalho na cultura e na historiografia da ciência portuguesa
}

\author{
Joaquim de Carvalho in portuguese culture and historiography \\ of science
}

BRUNO J. NAVARRO

Universidade Nova de Lisboa | Portugal

\begin{abstract}
RESUMO O presente artigo debruça-sesobre a obra historiográfica de Joaquim de Carvalho, um dos maiores vultos da cultura portuguesa, no século XX, procurando individualizar e sistematizar uma apreciação aos seustrabalhos precursores na área específica da História da Ciência, que muito contribuíram para a consolidação dessa área disciplinar em Portugal. Depois de uma breve apresentação biográfica, contendo os principais momentos da sua vivência académica e política, e de uma síntese do conjunto de apreciações críticas à sua obra, estabelecem-se as premissas conceptuais e metodológicas que nortearam a sua investigação, no campo da historiografia da ciência, procurando relevar o carácter inovador das suas abordagens face ao tradicionalismo historiográfico português.
\end{abstract}

Palavras-chave Joaquim de Carvalho - biografia - historiografia da ciência - história da ciência em Portugal.

\begin{abstract}
This article focuses on the historiographical work of Joaquim de Carvalho, one of the greatest figures of Portuguese culture in thetwentieth century. We aim to analyse and systematize his ground breaking work in History of Science, which contributed to the consolidation of this area of knowledge in Portugal. After a brief biographical review (with the key moments of his academic and political careers), and an over view of the set of critical assessments of his work, we examine the conceptual and methodological assumptions that guided his research in the field of Historiography of Science. We seek to reveal the innovative nature of his approach and how it differed from the Portuguese historiography traditionalism.
\end{abstract}

Keywords Joaquim de Carvalho - biography - historiography of science - history of Science in Portugal.

\section{Introdução}

Joaquim de Carvalho é hoje uma figura quase esquecida da cultura portuguesa. Desconhecido do grande público, pelo qual nunca manifestou particular empatia, é, no meio académico, uma presença fantasmática: o seu nome é genericamente reconhecido e associado a uma obra singular, em torno da cultura lusitana, mas são raros os estudos recentes a ele dedicados, vulgarizando-se a ideia de uma personalidade excessivamente complexa e erudita, de pensamento intrincado e soporífero que, por regra, se remete, com alívio, para o remanso das relíquias intocáveis.

A progressiva edição da sua obra completa, pela Fundação Calouste Gulbenkian, veio revelar a dimensão do seu legado científico, invulgarmente denso e heterogéneo, que se distende pelas áreas temáticas da Filosofia e História da Filosofia, História da Cultura, História e Crítica Literária, História das Instituições e Pensamento Político, entre outros 
escritos sobre a Universidade de Coimbra, onde exerceu o seu marcante magistério, e demais ensaios e fragmentos filosóficos e bibliográficos.

Finalmente, Joaquim de Carvalho surge-nos, em 2011, como objecto de estudo de umainvestigação para 0 Programa Doutoral em História, Filosofia e Património da Ciência e da Tecnologia, por ter sido um dos precursores da História da Ciência em Portugal, faceta ainda menos conhecida do seu profícuo percurso académico, mas que, peloprotagonismo que assumiu na consolidação dessa área disciplinar, impõe uma abordagem crítica, necessariamente breve e incompleta, que pretendemos ver enriquecida com uma sistematização da informação biográfica do autor e com uma síntese do conjunto de apreciações críticas à sua obra.

\section{Uma vida na Academia}

Joaquim de Carvalho, filho de Manuel José de Carvalho e Ana Ferreira dos Santos, nasceu a 10 de Junho de 1892, na Figueira da Foz, ali completando o ensino básico e secundário, depois de alguns anos da sua infância passados na aldeia ribatejana de Cem Soldos (Madalena - Tomar) ${ }^{1}$. Na Universidade de Coimbra concluiu a licenciatura em Direito (1909-1914), bacharelato em Letras, na secção de Ciências Históricas e Geográficas (1915), sendo nomeado professor assistente provisório nas aulas práticas de História da Filosofia Antiga, História da Filosofia Moderna e Moral (19161917). Concluiu o doutoramento em Ciências Filosóficas, defendendo a tese "António Gouveia e o Aristotelismo da Renascença" (1917), assumindo, desde logo, a regência da Cadeira de História da Filosofia Moderna (1917-1918). Em 1918 prestou provas para o magistério universitário, no grupo de filosofia, com a dissertação “Leão Hebreu,filósofo: para a história do platonismo no Renascimento" e, em 1919, é nomeado, por distinção, professor catedrático da Faculdade de Letras da Universidade de Coimbra, com dispensa de provas públicas.

0 seu percurso profissional esteve, desde então, permanentemente associado ao meio académico coimbrão, exercendo as funções de investigador e docente naquela instituição de ensino, assumindo, durante alguns anos (1921-1926), a regência da cadeira de História da Educação, na Escola Normal Superior de Coimbra (de que também foi secretário), mais tarde integrada na Secção de Ciências Pedagógicas da Faculdade de Letras da Universidade de Coimbra², e aderindo ao movimento progressista da Universidade Livre, concebida para o fomento da educação popular (1919)³. Em 1953, ministrou dois cursos ("Evolução da Cultura Filosófica em Portugal" e "Filosofia de Espinosa") na Faculdade de Filosofia da Universidade de S. Paulo, promovendo também algumas conferências na Faculdade Nacional de Filosofia da Universidade do Brasil, no Rio de Janeiro4. Foi ainda Administrador da Imprensa da Universidade de Coimbra (1921-1934), Director da "Revista da Universidade de Coimbra", Director do Instituto de Filosofia da Faculdade de Letras (1926), Bibliotecário e Director da Biblioteca Geral da Universidade de Coimbra (1934), Director do Laboratório de Psicologia Experimental (1938-1939), Secretário da Faculdade de Letras (1940), membro da direcção das revistas Universitatis Conimbrigensis Studia ac Regestae Acta Universitatis Conimbrigensis, fundador e director da "Revista Filosófica", da "Colecção Filosófica" (da livraria Atlântida) e dos "Ineditaac Rediviva - Subsídios para a História da Filosofia e da Ciência em Portugal (1951-1958)"

Eleito Sócio Correspondente da Academia de Ciências de Lisboa, para a Classe de Letras, em 1922, por proposta de António Baião, ocupou, dez anos mais tarde, como Sócio Efectivo, a cadeira da Classe de Ciências, deixada vaga por Francisco Luís Pereira de Sousa6 ${ }^{6}$. Foi ainda Sócio Permanente do Instituto de Coimbra (1926), sócio correspondente da Pontifícia Academia Tiberina (1932), académico correspondente da Academia de Belas Artes de Valladolid (1934), sócio efectivo da Sociedade de Geografia de Lisboa (1944), sócio honorário da Sociedade Espanhola de Filosofia, sócio honorário do Gabinete Real Português de Leitura (1953), membro do Instituto Internacional de Filosofia, "Moderator" da SocietasSpinozana de Haia, Membro da Academia Internacional da História das Ciências, condecorado com o grau de Cavaleiro da Legião de Honra, em França, Doutor Honoris Causa pelas universidades de Montpellier, Salamanca e Brasil, no Rio de Janeiro?. 
Iniciado na Maçonaria Portuguesa, em 1912, na loja A Revolta, de Coimbra, com o nome simbólico Guyau, atingindo, em 1919, o grau $7^{\circ}$ do $\mathrm{RF}^{8}$, Joaquim de Carvalho foi um republicano histórico, liberal, laico, muito afeiçoado aos ideais humanistas e aos ensinamentos do constitucionalismo oitocentista ${ }^{9}$, empenhado na implementação da I República portuguesa, e militando, mais tarde, no Partido Republicano da Reconstituição Nacional, liderado por Álvaro de Castro, com quem mantinha uma estreita relação pessoal. Isso não impediu, porém, que em 1919 se insurgisse vigorosamente contra o decreto governamental, da iniciativa do Ministro da Instrução, Leonardo Coimbra, determinando a desanexação da Faculdade de Letras da Universidade de Coimbra, com o objectivo de a transferir para a cidade do Porto. A sua reacção pública terá sido determinante para travar a intenção política do poder executivo ${ }^{10}$. Anos mais tarde, a sua declarada oposição ao Estado Novo e ao exercício personalista do poder de Oliveira Salazar, integrando, entre outros movimentos contestatários, Aliança Republicano-Socialista (1931), o Grupo de Estudos Democráticos (1931), e o Grupo de Renovação Democrática, e promovendo a fundação do Diário Liberal (1933), resultará em nova represália política, que precipitou a extinção da Imprensa da Universidade de Coimbra (1934), onde, desde 1921, encorajara a edição de centenas de obras académicas, de natureza histórica, literária e filosófica, subordinadas à cultura portuguesa, impulsionando, assim, uma viragem na vocação inicial da instituição, até esse momento exclusivamente voltada para o trabalho tipográfico ${ }^{11}$. Com essa violência administrativa, ditada pelo governo presidido por um homem que o seu entendimento reduzia à condição de seminarista hipócrita, "ressentido e frustrado"12, haveria de desencadear o seu progressivo afastamento da vida pública nacional, inteiramente substituída pelo isolamento do labor intelectual. A Imprensa da Universidade só viria a ser reactivada passados sessenta e quatro anos.

\section{Uma obra multifacetada}

Joaquim de Carvalho é autor de uma obra profusa e multifacetada que reflecte amplamente a sua curiosidade intelectual irrestrita e uma prodigiosa capacidade de trabalho ${ }^{13}$. Os seus trabalhos precursores na área da história da cultura e da filosofia portuguesas, constituem, ainda hoje, um legado absolutamente ímpar e incontornável, recorrentemente incensado pelo tradicionalismo académico, mas, nem por isso, isento de crítica. Alberto Ferreira foi, porventura, o seu glosador mais ostensivo ao identificar, nos seus trabalhos, uma excessiva vinculação ao espírito racionalista, positivista e historicista; uma atitude dúbia, relativamente aos modelos de abordagem historiográfica e às concepções filosóficas que veiculou; uma excessiva propensão para a metodologia analítica, que se comprazia do seu eruditismo passivo, da especulação gratuita e confirmação heurística, em detrimento da indispensável exegese, da visão de conjunto e do conveniente enquadramento histórico, cultural e filosófico. 0 professor coimbrão é, por isso mesmo, apresentado como um "aristocrata do espírito", de uma "passividade búdica", no contexto das lutas ideológicas e da intervenção social14. Barahona Fernandes, no elogio histórico que dedicou a Joaquim de Carvalho, sintetizaria as principais objecções feitas à sua obra, pelos seus contemporâneos:

Para uns, Joaquim de Carvalho foi demasiado personalista e, sobretudo, culturalista, apreendendo, apenas, a história do ângulo racionalista ideal, sem considerar as estruturas sociais e económicas e o contexto cultural e de classe, no conjunto de cada época. Para outros, cultivou com excessiva acentuação a positividade dos dados históricos e culturais - a factualidade objectivante - sem valorar a tradição mítica e mística e os dados de inspiração irracional e inconsciente ${ }^{15}$.

Mais recentemente, Fernando Catroga, avaliando o contributo historiográfico de Joaquim de Carvalho, advertiu os jovens investigadores para a natureza discutível da sua "concepção de um tempo histórico evolutivo e continuísta - a história contemporânea tende a operar com descontinuidades - bem como a sua redução da ideia de documento ao documento escrito e a confinação da cultura às criações das elites"16.

Detenhamo-nos, por instantes, na análise da intencionalidade subjacente à sua produção académica, dispensando-nos da ociosa tarefa de avaliar o seu valor intrínseco e a sua actualidade científica. Em 1919, por ocasião da 
crise institucional, desencadeada pela decisão governamental de encerrar a Faculdade de Letras da Universidade de Coimbra, por alegadamente ali se cultivar, anacronicamente, a especulação metafísica e uma erudição essencialmente livresca, Joaquim de Carvalho, rejeitou de forma veemente as acusações de proximidade com a atitude escolástica e tomista no ensino e na investigação. Os seus mais devotados admiradores, diante da dificuldade de lhe atribuírem uma mundividência epistemológica peculiar, sublinharam o carácter evolutivo de um verdadeiro "Homem teorético", em conformidade com o permanente devir da própria Filosofia ${ }^{17}$. Intelectual formado nos ideais do "positivismo doutrinal" e do "cientismo naturalista", o seu pensamento teria, assim, progredido no sentido do criticismo neokantiano de Marburgo (que "intenta superar tanto o positivismo e o materialismo, como o construtivismo da filosofia romântica"18), integrando a "positividade na reflexão crítica"19. Mas, nessa síntese filosófica evolucionista, teria sido também inspirado pela dúvida metódica de Descartes ${ }^{20}$; pelo racionalismo e "intuição fundamental" de Espinosa ${ }^{21}$; pela historicidade hegeliana, devidamente libertada das "clausuras do sistema" (que conduziam ao historicismo céptico e à filosofia ideológica) ${ }^{22} \mathrm{e}$ aplicada, à semelhança de Dilthey, aos fenómenos culturais e espirituais, que enquadravam externamente a acção da filosofia23; pela aspiração a uma cultura universal, respigada de Leibniz; culminando na sua adesão à fenomenologia de Husserl, que influenciou os seus trabalhos finais dedicados à problemática da saudade portuguesa ${ }^{24}$. Barahona Fernandes, no bosquejo encomiástico que dirigiu ao seu antecessor na cadeira da Academia das Ciências de Lisboa, identificou "a crítica sistemática, a dúvida metódica, a inquirição probatória" como os instrumentos de trabalho científico que municiavam o seu putativo "método histórico-evolutivo"25.

No momento da sua morte, em Coimbra, a 27 de Outubro de 1958, acalentava, ainda, a esperança do poder erigir uma obra monumental de História da Filosofia em Portugal, que reflectisse a historicidade do pensamento português, que estabelecesse uma abordagem externalista, contextualizando a acção dos seus protagonistas, no ambiente cultural nacional e internaciona ${ }^{26}$. Esse propósito académico decorria da aceitação do postulado hegeliano segundo o qual "um povo se encontra em condições de cultivar a filosofia quando, superada a via instintiva, concreta e material, ascende a um certo grau de espiritualidade"27. Acreditando na especificidade do pensamento filosófico nacional, que considerava vinculado à consciência colectiva do povo português, Joaquim de Carvalho atribuía uma dimensão muito abrangente ao conceito de "cultura filosófica", cabendo ao historiador "examinar as diversas manifestações culturais da comunidade portuguesa, nomeadamente as religiosas, as científicas, as literárias e as políticas, para além, naturalmente, das filosóficas" ${ }^{28}$. E nessa comunhão espiritual entravam não apenas os autores que se envolveram no debate filosófico nacional, mas também os que, apesar de conservarem uma ligação quase imperceptível ao país, eram portugueses pelo nascimento, consequentemente conectados, por essa via, ao espírito lusitano ${ }^{29}$. Alberto Ferreira haveria de sublinhar, na obra de Joaquim de Carvalho,

sobrevalorização da contribuição dos portugueses que se realizaram fora do país, estranhos, portanto, ao condicionalismo que nos determinou por dentro. A não separação entre o que aqui se pensou, tal qual se pensou e nas condições inteiramente nacionais, e o que se pensou fora do país, sem o ter em grande conta nem por ele ser influenciado, gera uma ilusão: a existência de uma inteligência típica, essencial, inata - a chamada «alma portuguesa» capaz de circular no sangue de Pedro Hispano, Francisco Sanches, Espinosa e Oróbio de Castro, sem citar todos os outros que escreveram e se notabilizaram fora do país ${ }^{30}$.

Por outro lado, este aparente "preconceito ideológico de carácter nacionalista"31 gera um outro equívoco. É que embora Joaquim de Carvalho manifestasse o seu cepticismo relativamente aos pressupostos de uma "aclimatação pura e simples de doutrinas estrangeiras", em Portugal32, a verdade é que, como notou também Alberto Ferreira, o método que utilizou nos seus estudos de cultura filosófica

inclinaram-no para uma concepção europeizante, para a interpretação do pensamento português segundo padrões firmemente estabelecidos pelo racionalismo objectivo dos historiógrafos de grande exigência documental e fidelidade aos textos que assinalam o surto dos estudos de história do pensamento na Alemanha, na França, Inglaterra e em parte também na Itália ${ }^{33}$. 


\section{Contribuições pioneiras na Historiografia da Ciência}

0 contributo historiográfico de Joaquim de Carvalho, no âmbito da História da Ciência, por si considerada uma "sub-disciplina da História"34, deve ser entendido à luz daquele desígnio maior de interpretação da identidade nacional, através do pensamento filosófico português, entendimento que deixou bem patente quando afirmou que, "independentemente da ciência em si mesma e da sua metódica, nós podemos considerar a morfologia do saber como expressão visível de uma essência, na qual se reconhece, como no próprio saber, o poder criador do espírito"35.

Pina Martins, um dos seus mais dedicados biógrafos, responsável pela edição integral da sua obra, teve o cuidado de assinalar, em Joaquim de Carvalho, a ausência de uma formação de base científica, lacuna que, nas reflexões históricas e críticas sobre ciência, que nos legou, procurou colmatar com a consistência dos seus conhecimentos filosóficos e com uma curiosidade e disponibilidade intelectual irrestrita ${ }^{36}$. Orlando Ribeiro deu-nos conta do seu comprazimento no convívio com os cientistas ${ }^{37}$, facto que fica bem ilustrado na correspondência epistolar que manteve com Duarte Leite, Fontoura da Costa, Manuel Ramos e Leite de Vasconcelos, entre outros ${ }^{38}$, sendo também assinalada a influência que exerceu nas obras de Silva Dias, Rómulo de Carvalho e Luís de Albuquerque, contribuindo decisivamente para "desviar" a história da ciência em Portugal da "memória dos descobrimentos"39. Em 1934 integrou o Comité Central do Grupo Português de História das Ciências, dinamizado por Arlindo Monteiro, por instigação de Aldi Mieli (na sequência da constituição da Académie Internationale d'Histoire des Sciences, em Paris), participando no III Congresso Internacional de História da Ciência e colaborando activamente na revista "Petrus Nonius. Publicação do Grupo Português de História das Ciências" (1937-1951), primeira publicação portuguesa dedicada à literatura científica ${ }^{40}$. Em 1941, foi figura de destaque no Congresso do Mundo Português, coordenando os painéis das Ciências Físico-Matemáticas e Militares, Ciências Naturais e Biológicas, Ciências Médicas e Ciências Sociais e Morais ${ }^{41}$ onde reuniu a elite científica nacional, em redor da História da Actividade Científica Portuguesa ${ }^{42}$.

Apesar de tudo, a sua eleição para sócio efectivo da Academia de Ciências de Lisboa, na classe de Ciências (recorde-se que enquanto sócio correspondente pertenceu à Classe de Letras) terá resultado, essencialmente, da verificação prática de uma oportunidade estatutária, que permitiu acelerar a sua vinculação à academia científica portuguesa, atendendo ao prestígio que Joaquim de Carvalho adquirira nos círculos culturais nacionais e internacionais. A sua admissão naquela classe científica terá contribuído, positivamente (segundo Barahona Fernandes), para "integrar as Ciências especiais na Cultura e na Filosofia"43.

Na década de quarenta foi convidado para, no âmbito da actividade editorial daquela instituição, integrar a comissão encarregada da edição das obras completas de Pedro Nunes, empresa de grande alcance historiográfico e científico, interrompida em 1958, na sequência do falecimento de Joaquim de Carvalho, e recentemente reiniciada pelo historiador da ciência, Henrique Leitão. As anotações que então introduziu nos textos originais daquele notável matemático e cosmógrafo português, revelam, irrefutavelmente, uma grande admiração pessoal e intelectual, que se reflecte, na adopção deliberada de um registo literário impressivo, de figurino laudatório, laborando, não raras vezes, no campo da especulação pura, sem sustentação documental, caucionando interpretações baseadas em meras sugestões e conjecturas, que aparentam querer reforçar a ideia de excepcionalidade do seu objecto de estudo ${ }^{44}$. Esta constatação não obscurece, porém, a dimensão singular do conhecimento que demonstrava possuir da vida e obra de Pedro Nunes, do domínio absoluto do campo temático e terminologia científica que the estão associados, bem como da multiplicidade de recursos arquivísticos e bibliográficos, nacionais e internacionais, de que foi um dos mais dedicados exploradores. Serve apenas para confirmar a sua identificação com aquela primeira vaga de historiadores portugueses da ciência apostados em reconstituir os cânones da identidade nacional (não esqueçamos a sua colaboração nos movimentos intelectuais da Renascença Portuguesa e da Seara Nova), celebrando os feitos dos seus vultos maiores, inicialmente respigados da gesta da expansão ultramarina, para depois contemplarem também as "personalidades setecentistas e oitocentistas", gloriosamente resgatadas das sombras da memória pátria, subitamente alcandoradas à dignidade estatutária de "heróis do passado científico"45. Também nesse capítulo, Joaquim de Carvalho teve um papel precursor quando se lançou nos estudos biográficos de Jacob de Castro Sarmento (1691-1762) - médico português, que, em 
Inglaterra, foi aceite no Royal College of Physicians e na Royal Society of London - e de João Jacinto de Magalhães (1722-1790), cientista expatriado que também se radicou na velha Albion, sendo sócio correspondente da mesma sociedade científica londrina, das academias de ciências de Bruxelas, Lisboa, Madrid, Berlim, Paris, São Petersburgo e das "Sociedades Filosóficas de Filadélfia, de Harlem e de Manchester"46.

Finalmente, deixou-nos dois textos essenciais para podermos sondar as suas lucubrações filosóficas e historiográficas aplicadas ao processo científico: "Newton e o ideal de Ciência Moderna", originalmente publicado na Revista da Faculdade de Ciências da Universidade de Coimbra, em 1932, e o "Discurso proferido na sessão inaugural do Instituto de Altos Estudos", no mesmo ano, editado, na sua Obra Completa, com o título "O ideal moderno de ciência". Como vimos anteriormente, é possível identificar, em Joaquim de Carvalho, a influência hegeliana de historicidade geral do desenvolvimento da ciência, que envolve, não apenas a sua realidade idiossincrática, mas também os factores que lhe são extrínsecos:

Sob o acontecer humano, tão vário e contingente, flui sem dúvida o sumus, ou seja, a relação sociologicamente impessoalizada de homem para homem, mas flui também o ego, ou seja, o homem concreto e pessoal, quero dizer, os fins que prossegue, os valores a que adere ou cria e o conceito que da sua essência e significação no universo forma - fins, valores e essências tão autónomas e irredutíveis, que todos distinguimos como espécies do género humano, dentre outras, o homo faber, o homo credulus, o homo politicus e o homo sapiens. Cada uma destas espécies tem logicamente a sua diferença específica, a qual dita comportamentos diversos em face da vida e do universo (... $)^{47}$.

A evolução do conhecimento científico deve, pois, ser percepcionada numa perspectiva externalista, uma vez que "é nas modificações que se operam no homem vivo e real e não nas relações entre conceitos do pensamento abstracto que devemos procurar a evolução das concepções gerais, que orientam a conduta"48. Alguns anos mais tarde, manteria a mesma convicção, concretizando que

a história genética de alguns problemas e a desenvolução da marcha do espírito no sentido do respectivo esclarecimento ou demonstração encontram por vezes a compreensão cabal, quando não explicação exacta, em acontecimentos da vida pessoal ou da situação social ${ }^{49}$.

Mas se adoptou, de forma tão assertiva, esta epistemologia externalista, que faz depender a evolução científica de uma multiplicidade de factores externos à própria ciência, o mesmo já não sucedeu quando procurou identificar os responsáveis pela dinâmica científica, fazendo recair o mérito na capacidade genial do indivíduo. Partilhava, por isso, com Bertrand Russel, a ideia de que

se tivesse morrido na infância aquela centena de homens do século XVII, cujos nomes veneramos, não existiria mundo hodierno. É, pois, uma ilusão de certa escola sociológica o menosprezo da inteligência para atribuir os grandes sucessos a causas impessoais (...), e não apenas ilusão, porque nela veja um perigo. A natureza qualitativa dos factos culturais só vive na atmosfera das grandes altitudes. O ar da planície sufoca-a e mata-a; e o perigo a que aludo (...), consiste na possibilidade da mentalidade de massa, sem curiosidades ultra-vitais e sem vigílias, deslumbrada pelo progresso, isto é, pela técnica, rendida ao realismo sensorial, grosseiro e vagabundo, invadir a zona tenuíssima da minoria desinteressada, e, julgando a qualidade irreal pela quantidade mensurável, estancar a seiva que nutre o progresso ${ }^{50}$.

Consequentemente, também não perfilhava a teoria de continuismo histórico da ciência, assumindo a inevitabilidade das descontinuidades intrínsecas a uma ciência que evolui de modo fragmentário, desenvolvida em conformidade com as interrogações específicas que a cada momento são formuladas no plano da racionalidade:

Tempos houve, bem próximos de nós, em que se tornou lugar-comum do progresso contínuo e quase fatal, toda a gente traduzindo na realidade a admirável comparação de Pascal entre a humanidade e um 
homem que vivesse longos anos e aprendesse sempre. Hoje sabemos que esta moção é uma representação subjectiva e que nada comprova cientificamente a existência de continuidade histórica como marcha crescente para o mais completo e para o melhor ${ }^{51}$.

Esta concepção historiográfica aplicada especificamente à evolução do conhecimento científico, envolvia, naturalmente, um conjunto de questões metodológicas complexas, uma vez que, por um lado, "uma das maiores dificuldades com que se depara o historiador da ciência é o facto dos descobrimentos se apresentarem quase sempre com a respectiva fundamentação lógica e não segundo a ordem cronológica da constituição"52; por outro lado, e num plano mais abrangente, porque

a unicidade e a singularidade irreversível dos factos históricos não permitem a redução à identidade, a qual constitui a essência da explicação científica, e ainda porque, pela natureza do processo psicológico que põe em exercício, a história decorre no espírito do historiador num plano de actualidade" ${ }^{\prime 3}$.

Diante destes obstáculos,

o facto cultural, seja filosófico, científico ou artístico, é, no advento e na persistência, a coisa mais subtilmente frágil do planeta, tão frágil e delicada, que, ao contrário das coisas concretas, que nos resistem, a sua simples existência carece incessantemente de ser compreendida. Que haja eclipses no processo compreensivo ou assimilador, e o homem volver-se-á intelectual ou emocionalmente cego para o que o deslumbraram os seus genitores ${ }^{54}$.

Estas advertências são bem reveladora dos pruridos epistemológicos de Joaquim de Carvalho, que aparentemente pretendia resguardar-se do risco de abordagens anacronistas ou presentistas, optando pela "via da compreensão mediante um método fenomenológico", com o qual vislumbrava a possibilidade de "raptar os conteúdos e formas de vida que servem de fundamento ao processo histórico"55.

É pois, diante desta perspectiva que coloca as suas reflexões em redor do advento da ciência moderna, "aquele incomparável instante em que o europeu culto do final do século XVI sentiu e pensou a necessidade vital de um novo ideal de ciência, de uma nova metódica, de uma nova problemática e de uma nova equação da mente com a realidade"56. Descartes (o artífice de uma concepção nova de dedução), Galileu (o grande teórico e realizador do método experimental, a quem a Humanidade deve "o trânsito decisivo para a via científica, ao operar a revolução imensa de trocar a reflexão do porquê pelo como do movimento, e os pressupostos da física aristotélica pelos conceitos matemáticos de tempo e espaço"), e Newton (o "experimentador ideal" e um "teórico do método", que "prosseguiu e radicou o ideal de ciência moderna, a-histórico e geométrico"; que estabeleceu definitivamente "a unidade das lei dos mundos terrestre e celeste, mediante as quais o universo alcançou a simplicidade e harmonia de um Cosmos" e que

fundamentou cientificamente a concepção mecânica da natureza, considerada como um sistema de objectos físicos em movimento, explicável por um mínimo de relações entre elementos reais e homogéneos"), foram os grandes protagonistas dessa grande modificaçã $0^{57}$.

No século XVII, o ideal do conhecimento científico da natureza, dinâmico e "tenso para o futuro", radicado no número e na medida, para explicar, pela observação e experimentação, a "eliminação do diverso e a redução à identidade", instituiu um novo paradigma que superou o ideal aristotélico-escolástico, onde predominara uma "atitude valorativa", contemplativa e estática, que entendia o homem como um valor central e absoluto e que pretendia "dominar 0 diverso e o múltiplo da experiência sensível", pela especulação abstracta ${ }^{58}$. Em Portugal, apesar dos esforços de alguns "franco-atiradores", como Castro Soromenho, Ribeiro Sanches e Verney, só a partir de 1779, com o estabelecimento da Academia Real das Ciências, foi possível introduzir o espírito científico do século XVII. Um atraso que Joaquim 
de Carvalho explica, no plano social, pela incapacidade de acompanhar a revolução económica que "transformou as condições materiais de vida"; no plano sentimental, pelo imobilismo social, avesso à novidade, cristalizado nos valores nobiliárquicos e na repartição tripartida dos estados, que obstaculizaram a emergência da classe burguesa; e, finalmente, no plano intelectual, motivado por uma "mentalidade intuspectiva", arreigada a um conservadorismo obstinado, incapaz de assimilar a mudança e indiferente à natureza física ${ }^{59}$. Neste contexto, adquirem, efectivamente, uma relevância inusitada, figuras como Jacob de Castro Sarmento, o introdutor do newtonianismo em Portugal, que baldadamente se empenhou num projecto de renovação da cultura portuguesa ${ }^{60}$, e João Jacinto de Magalhães que, apesar de não ter anunciado uma inovação científica revolucionária, afirmou-se como um inventor "amador", exímio construtor de instrumentos de precisão, correspondendo ao

típico representante da atitude científica do seu tempo, enquanto actividade que se orienta exclusivamente para a observação e para a experimentação em ordem ao estabelecimento de leis e ao acréscimo e exactidão dos conhecimentos, sem se empenhar na formulação de teorias gerais e na reflexão de teorias gerais e na reflexão de dificuldades epistemológicas ${ }^{61}$.

\title{
Conclusão
}

Em 1958, alguns meses antes do seu falecimento, ocorrido a 27 de Outubro, Joaquim de Carvalho dedicou um pequeno estudo ao contributo de Ricardo Jorge,conhecido médico, professor e investigador portuense, para a historiografia cultural portuguesa. Reconhecia nesse trabalho um sentido historizante, que combinava o "exame actual do objecto com a respectiva consideração histórica", sinergia que considerava radicada, ideologicamente, "no evolucionismo e no positivismo dominantes" daquele tempo histórico. Diversamente do que sucediacom a quase generalidade dos seus contemporâneos, Ricardo Jorge não limitara a sua análise de historiador ao apuramento dos factos, pela pormenorização das análises e suas íntimas correlações. Nos seus trabalhos

a indagação biográfica não se separou dos movimentos de ideias e, em especial, do teor das conjunturas histórico-culturais e das exigências inerentes à actividade científica. É a convicção profunda no valor próprio e autónomo da ciência que anima as suas páginas histórico-científicas, por forma que elas conjugam, a um tempo, a informação retrospectiva e a concepção normativa de que somente a ciência proporciona a explicação consistente e coerente. Daqui o alcance das suas investigações biográficas, visto relacionar o homem com as circunstâncias em que lhe foi dado trabalhar e com o estado da ciência na conjuntura em que ele viveu ${ }^{62}$.

0 elogio a Ricardo Jorge, com quem partilhava, inquestionavelmente, a concepção da experimentação como critério fundamental de verdade, servia, essencialmente, como referencial legitimador da metodologia que o próprio Joaquim de Carvalho aplicou aos seus trabalhos precursores, no âmbito da história da ciência, essa nova sub-disciplina da História, que não podia deixar de atrair a atenção de um espírito indagador, dotadode uma curiosidade intelectual insaciável, que extravasava largamente os limites da sua formação universitária de base:

\begin{abstract}
A história da ciência é hoje uma disciplina consagrada; nenhum outro ramo de conhecimentos se lhe avantaja em benefícios morais pois logra inundar de sentido a noção de progresso, patenteando a influição das evoluções e revoluções dos conhecimentos exactos nas nossas mundividências e necessidades de adaptação e senhorio da Natureza, isto é, nos juízos do homem sobre si próprio e sobre o Mundo, e na maravilhosa aplicação instrumental da técnica à utilização e domínio das brutas e cegas forças naturais ${ }^{63}$.
\end{abstract}

Porém, ao invés do mestre portuense, Joaquim de Carvalho, modelo de espírito culto, mundividente e irrequieto, figura tutelar da academia portuguesa da primeira metade do século XX, não possuía uma formação de base científica, 
socorrendo-se, para a colmatar, da sua sólida erudição bibliófila. E apesar da aparente consonância metodológica com aquele outro investigador, os seus trabalhos historiográficosteriam atendido, na sua opinião, às interrogações que, no seu tempo, foram colocadas por novas correntes epistemológicas e pela emergência da sociologia cultural, que impunham a perscrutação de uma "exuberante problemática", por ele próprio enfeixadas

em três tópicos fundamentais, a saber: o exame das tentativas e esforços despendidos em beneficio do progresso científico, a colheita dos resultados obtidos e, finalmente, a observação da morfologia e objectivos da actividade científica ${ }^{64}$.

Para solucionar todaessa nova problemática, não deixou de recorrer à utensilagem conceptual e metodológica, histórico-filosófica, evolutivo-continuista, de um positivismo historicista, devidamente integrado na reflexão crítica, que aplicou, de uma forma geral, a todos os seus trabalhos correlativos à dimensão global da cultura portuguesa, e à história das ideias, de que a história da ciência seria apenas mais uma variante. A ela recorreu para se precaver dos vícios do determinismo científico, das abordagens internalistas e dos perigos dos anacronismos. Em concordância com Paul Tannery também ele integrou a história da ciência na história geral da humanidade ${ }^{65}$. À semelhança de Alexandre Koyré,seu contemporâneo, também ele rejeitava a ideia comtiana de progresso cumulativo e continuado da ciência, salientando o seu carácter fragmentário e intermitente. E muito antes de Thomas Kuhn (celebrado opositor da teorização positivista do fenómeno da ciência)reflectir sobre as estrutura das revoluções científicas, já ele referenciava explicitamente umamudança de "paradigma" para se referir ao momento da superação do modelo escolástico, por uma nova concepção de mundo, no século XVII, orientada pelo "ideal da ciência moderna"66.

Mas ao envolver o passado científico no seu programa fenomenológico, em busca da essência do pensamento filosófico português (de cariz europeizante),sob a influência hegeliana de historicidade geral do desenvolvimento da ciência, já não teve o ensejo de se eximiràs idiossincrasias do tradicionalismo historiográfico (e nacionalista), que muitas vezes desaprovara, ao patrocinar a construção de uma história elitista, especulativa e idealizada, destinada a enriquecer uma putativa galeria de notáveis, de cuja acção genial estava intrinsecamente dependente o devir histórico da dinâmica científica.

Ao enredar-se nessas considerações valorativas, poder-se-ia colocar, ele mesmo, na posição quefixou para Ricardo Jorge, quando, naquele texto de 1958, escrito já no ocaso de uma vida plena de reflexões epistemológicas, rejeitou elevar aformulação de juízos gerais, de natureza historiográfica, a um qualquer estatuto normativo, vinculativo:

os juízos (...), pelo que contêm ou implicam de generalização e de apreciação valorativa, testemunham, sem dúvida, o talento de Ricardo Jorge, mas são intrinsecamente verosímeis, como o são, aliás, todos os juízos históricos, que jamais podem alcançar a exactidão e o rigor dos juízos científicos. Uma reconstrução e valoração histórica nunca pode considerar-se definitiva e acabada, porque a história é uma reconstituição em permanente revisão e os juízos com que ela se constrói são intrinsecamente correlações dependentes de múltiplas circunstâncias, desde o volume e densidade dos factos considerados à consciência intelectual e à capacidade imaginativa do historiador. Isto não quer dizer que os juízos histórico-valorativos de Ricardo Jorge sejam circunstanciais e hajam perdido actualidade. Não. Coerentes com o estado dos conhecimentos no seu tempo e com o sentido de positividade que lhe nutriu a mente - e nisto reside o fundamento da verosimilhança que possuem - eles são actuais, pelo menos como ponto de partida ou de contraprova, tanto mais que alguns incidem sobre temas que não foram retomados ${ }^{67}$. 


\section{Notas e referências bibliográficas}

Bruno J. Navarro é investigador integrado do Centro Interuniversitário de Histórias das Ciências e da Tecnologia (Universidade de Lisboa e Universidade Nova de Lisboa) e doutorando da Faculdade de Ciências e Tecnologia da Universidade Nova de Lisboa. E-mail: bjnavarro@gmail.com

1 Diário de Coimbra, 14 de Junho de 1975.

2 FERNANDES, Barahona. Joaquim de Carvalho - Pessoa e Atitude Espiritual. Miscelânea de Estudos a Joaquim de Carvalho, n. 9, Figueira da Foz, BibliotecaMuseu Joaquim de Carvalho, 1963, p. 891.

3 PEIXOTO, Jorge. A Imprensa da Universidade de Coimbra e a acção de Joaquim de Carvalho. In: AROUIVO DE HISTÓRIA E BIBLIOGRAFIA. $1923-1926$. Lisboa, Imprensa Nacional Casa da Moeda, 1976, p. XX-XXIV, v. 2.

$4 \quad$ Idem, p. 895

$5 \quad$ Cf. SANTOS, João Marinho dos; AZEVEDO e SILVA, José Manuel. A Historiografia dos Descobrimentos, através da correspondência entre alguns dos seus vultos. Coimbra: Imprensa da Universidade, 2004, p. 7-42. HOMENAGEM AO DOUTOR JOAQUIM DE CARVALHO NO $1^{\circ}$ CENTENÁRIO DO SEU NASCIMENTO, Coimbra: Biblioteca Geral da Universidade de Coimbra, 1994, p. 1-7; PEIXOTO, op. cit., 1976, p. XV-XXXV; Biblos. Revista da Faculdade de Letras, v. XXXIV, Coimbra, 1958, p. 663.

6 ACADEMIA DAS CIÊNCIAS DE LISBOA. Processo Acadêmico de Joaquim de Carvalho (tipos documentais variados; datas variadas). Localizado na Biblioteca da Academia das Ciências de Lisboa.

7 SANTOS; AZEVEDO e SILVA, op. cit. 2004, p. 28. FERNANDES, op. cit., 1963, p. 894.

8 Cf. MARQUES, A. H. de Oliveira. Dicionário de Maçonaria Portuguesa. Lisboa: Editorial Delta, 1986, cl. 286, v. 1.

9 PINA MARTINS, José V. de. Joaquim de Carvalho (1892-1958): o homem e a obra. In: CARVALHO, Joaquim de. Obras Completas de Joaquim de Carvalho. Lisboa: Fundação Calouste Gulbenkian, 1992, p. XIII, v. 1 (Filosofia e história da filosofia, 1916-1934).

10 Cf. PEIXOTO, op. cit., 1976, p. XV-XVIII. Ver também: SANTOS, João Marinho dos; AZEVEDO e SILVA, op. cit., 2004, p. 18-20.

11 PINA MARTINS, José V. de. Joaquim de Carvalho. In: CARVALHO, Joaquim de. Obras Completas de Joaquim de Carvalho. Lisboa: Fundação Calouste Gulbenkian, 1996, p. XIII-XIV, v. 8 (Ensaios e Fragmentos Filosóficos e Bibliográficos).

12 PEIXOTO, op. cit., 1976, p. XXXII.

13 PINA MARTINS, op. cit., 1996, p. XVI.

Numa breve introdução à obra de Joaquim de Carvalho o autor faz um exercício de delimitação, temática, não exaustiva, dos seus trabalhos: "Saber e filosofar, ciência e sabedoria, ideal moderno da Ciência, limites do ensaísmo, cultura castreja, a evolução da filosofia medieval portuguesa, a evolução da historiografia filosófica até ao século XIX, instituições de cultura e cultura filosófica e científica do período medieval, instituições de cultura no século XVI, pensamento português na Idade Média e no Renascimento, monumentos de arte tipográfica, o Humanismo português na época do Renascimento, problemática da saudade, os Descobrimentos portugueses, a Universidade de Coimbra na renascença e muitos, muitos outros temas que focou e desenvolveu através de investigações profundas ou de reflexões argutas, com uma mestria de domínio erudito e de método rigoroso dignos de um grande investigador e de um argumentador consumado".

14 FERREIRA, Alberto. Joaquim de Carvalho e a Cultura Portuguesa. Vértice. Revista de Cultura e Arte, Coimbra, v. XXI, n. 211, p. 235-244; v. XXI, n. 212, p. 325-337, 1961

15 Cf. FERNANDES, op. cit., 1963, p. 896.

16 Cf. CATROGRA, Fernando Catroga. Joaquim de Carvalho e a História. In: HOMENAGEM AO DOUTOR JOAQUIM DE CARVALHO NO $1^{\circ}$ CENTENÁRIO DO SEU NASCIMENTO. Coimbra: Biblioteca Geral da Universidade de Coimbra, 1994, p. 15

17 Cf. MALPIQUE, Cruz Malpique. Perfil intelectual e moral do Prof. Joaquim de Carvalho. Miscelânea de Estudos a Joaquim de Carvalho, n. 2, Figueira da Foz, Biblioteca-Museu Joaquim de Carvalho, p. 128-134, 1959.

18 PEIXOTO, op. cit., 1976, p. XVIII.

19 FERNANDES, op. cit., 1963, p. 906.

20 Cf. CARVALHO, José Maurício de. História da Filosofia e Tradições Culturais. Um diálogo com Joaquim de Carvalho. Porto Alegre: EDIPUCRS, 2001, p. 181195.

21 Cf. JORDÃO, Francisco V. Joaquim de Carvalho e Espinosa. 0 acordo de intenções no campo político-religioso. Revista Filosófica de Coimbra, Coimbra, n. 2. p. 309-319, 1992

22 CATROGA, op. cit., 1994, p. 12.

23 Cf. CARVALHO, op. cit., 2001, p. 239-243.

24 FERNANDES, op. cit., 1963, p. 907-911.

25 FERNANDES, op. cit., 1963, p. 897-903

26 RIBEIRO, op. cit., 1980, p. 5. Ver também PINA MARTINS, op. cit., 1992, p. XIV-XV.

27 MORUJÃO, Alexandre. Doutor Joaquim de Carvalho (1892-1958). Biblos. Revista da Faculdade de Letras, Universidade de Coimbra, v. XXXIV, 1958, p. 662.

28 COXITO, Amândio. Joaquim de Carvalho: antipositivismo e metafísica. In: HOMENAGEM AO DOUTOR JOAQUIM DE CARVALHO NO $1^{\circ}$ CENTENÁRIO DO SEU NASCIMENTO. Coimbra: Biblioteca Geral da Universidade de Coimbra, 1994, p. 18-21. 
29 FERREIRA, op. cit., 1961, p. 238-239.

30 COXITO, op. cit., 1994, p. 20.

31 MORUJÃO, op. cit., 1958, p. 662.

32 FERREIRA, op. cit., 1961, p. 239.

33 SIMÕES, Ana. História da Ciência. Lisboa: Academia de Ciências de Lisboa, 2010, p. 6. (Comunicação apresentada no Instituto de Estudos Académicos para Séniores).

34 CARVALHO, Joaquim de. 0 ideal moderno da Ciência. In: . Obras Completas de Joaquim de Carvalho. Lisboa: Fundação Calouste Gulbenkian, 1987, p. 297-298, v. 5 (História e Crítica Literárias. História da Ciência. 1925-1975).

35 PINA MARTINS, José V. de. Joaquim de Carvalho: crítico literário e historiador da ciência. In: CARVALHO, Joaquim de. Obras Completas de Joaquim de Carvalho. Lisboa: Fundação Calouste Gulbenkian, 1992, p. VII, v. 5 (História e Crítica Literárias. História da Ciência. 1925-1975).

36 Cf. RIBEIRO, op. cit., 1980, p. 1.

37 SANTOS; AZEVEDO e SILVA, op. cit., 2004, p. 15.

38 Cf. FITAS, Augusto J. S.; RODRIGUES, Marcial A. E.; NUNES, Maria de Fátima. Filosofia e História da Ciência em Portugal no século XX. Casal de Cambra: Caleidoscópio, 2008, p. 261

39 Idem, p. 221-260; ver também SIMÕES, op. cit., 2010, p. 6.

40 FITAS; RODRIGUES; NUNES; op. cit., 2008, p. 245-246.

41 CONGRESSO DO MUNDO PORTUGUÊS. 8., 1940, Lisboa. Discursos e comunicações apresentadas ao Congresso da História da Actividade Científica Portuguesa. Comissão Executiva dos Centenários. Secção de Congressos, 1940: v. XII, t. 1; $1^{\text {a }}$ Secção: Ciências Físico-Matemáticas e Militares; $2^{2}$ Secção, $1^{a}$ parte: Ciências Naturais e Biológicas. v. XIII, t. 2: 2ª Secção, 2ª parte: Ciências Médicas; $3^{a}$ Secção: Ciências Sociais e Morais.

42 FERNANDES, op. cit., 1963, p. 889

43 Cf. CARVALHO, Joaquim de. Obras Completas de Joaquim de Carvalho. História e Crítica Literárias. História da Ciência. 1925-1975. Lisboa: Fundação Calouste Gulbenkian, 1987, p. 315-659, v. 5.

44 Ver FITAS; RODRIGUES; NUNES; op. cit., 2008, p. 212-224.

45 CARVALHO, Joaquim. Correspondência científica dirigida a João Jacinto de Magalhães (1769-1789). In: Lisboa: Fundação Calouste Gulbenkian, 1992, p. XIII-XIV, v. 5 (História e Crítica Literárias. História da Ciência. 1925-1975).

46 CARVALHO, Joaquim. 0 ideal moderno de Ciência. In:__. Obras Completas de Joaquim de Carvalho. Lisboa: Fundação Calouste Gulbenkian, 1992, p. 299, v. 5 (História e Crítica Literárias. História da Ciência. 1925-1975).

47 Idem, p. 299, v. 5.

48 Cf. CARVALHO, Joaquim. Pedro Nunes: mestre do Cardeal-Infante D. Henrique. Nota breve a propósito de novos documentos nonianos da Biblioteca Eborense. In: _. Obras Completas de Joaquim de Carvalho. Lisboa: Fundação Calouste Gulbenkian, 1992, p. 318-319, v. 5 (História e Crítica Literárias. História da Ciência. 1925-1975).

49 Cf. CARVALHO, op. cit., 1992, p. 312-313 (0 ideal moderno de Ciência).

50 CARVALHO, Joaquim. Newton e o ideal de Ciência. In: ___. Obras Completas de Joaquim de Carvalho. Lisboa: Fundação Calouste Gulbenkian, 1992, p. 667-668, v. 5 (História e Crítica Literárias. História da Ciência. 1925-1975). Ver também, CARVALHO, op. cit., 1987, p. 312 , v. 5.

51 Cf. CARVALHO, op. cit., 1987, p. 702, v. 5. (0 ideal moderno de Ciência).

52 CARVALHO, op. cit., 1992, p. 702. (Correspondência científica dirigida a João Jacinto de Magalhães, 1769-1789).

53 CARVALHO, op. cit., 1992, p. 298 (0 ideal moderno de Ciência).

54 Idem, p. 313.

55 CARVALHO, op. cit., 1987, p. 665. (Newton e o ideal de Ciência Moderna).

56 CARVALHO, op. cit., 1992, p. 667-669 (Newton e o ideal de Ciência Moderna).

57 Idem.

58 CARVALHO, op. cit., 1987, p. 304-306. (0 ideal moderno de Ciência).

59 CARVALHO, Joaquim de. Jacob de Castro Sarmento et l'introduction des conceptions de Newton en Portugal. In: Carvalho. Lisboa: Fundação Calouste Gulbenkian, 1992, p. 675-678, v. 5 (História e Crítica Literárias. História da Ciência. 1925-1975).

60 CARVALHO, op.cit., 1987, p. 689-709. (Correspondência científica dirigida a João Jacinto de Magalhães (1769-1789)).

61 CARVALHO, op.cit., 1987, p. 211-212. (Ricardo Jorge na historiografia cultural portuguesa).

62 CARVALHO, Joaquim de. A actividade científica da Universidade de Coimbra na Renascença. Calouste Gulbenkian, 1992, p. 330, v. 3 (História da Cultura, 1922-1948). . Obras Completas de Joaquim de Carvalho. Lisboa:

63 Idem, p. 331.

64 KRAGH, Helge. Introdução à Historiografia da Ciência. Lisboa: Porto Editora, 2001, p. 16-17.

65 GAVROGLU, Kostas. O Passado das Ciências como História. Lisboa: Porto Editora, 2007, p. 50-57; 207-212.

66 CARVALHO, op.cit., 1987, p. 212-213. (Ricardo Jorge na historiografia cultural portuguesa).

[Recebido em Junho de 2013. Aprovado para publicação em Março de 2015] 